\title{
SIMULATION OF MOBILE FALSEWORK UTILIZATION METHODS IN BRIDGE CONSTRUCTION
}

\author{
$\mathrm{He}-\mathrm{Xu} \mathrm{Liu}$ \\ Ming-Fung Francis Siu \\ Ronald Ekyalimpa \\ Ming Lu \\ Simaan AbouRizk \\ University of Alberta \\ Construction Engineering and Management \\ Edmonton, Alberta, Canada
}

\author{
Sebastian Hollermann \\ Hans-Joachim Bargstädt \\ Bauhaus-Universität Weimar \\ Fakultät Bauingenieurwesen \\ Marienstraße 7A, D-99423 Weimar
}

\begin{abstract}
Scaffolds and shoring systems are generally referred to as the falsework in bridge construction, serving as temporary structures to support bridge span construction. The falsework cost usually accounts for 50-70\% of the total project concrete budget. Falsework installation and advancing methods can greatly impact the completion time and actual cost. Thus, simulation can be instrumental in planning bridge construction operations and analyzing various options by evaluating postulated "what-if" scenarios. This study uses a previously constructed bridge in Sweden as a case study to test three feasible construction sequence alternatives. One of these alternatives was implemented on the actual construction of this bridge. Modeling was performed in Simphony, which captures the unique construction sequence requirements and constraints, resulting in project durations for each alternative. Results from simulation experiments were corroborated by the construction engineer who had worked on the bridge project in terms of the advantages that each alternative method possesses.
\end{abstract}

\section{INTRODUCTION}

Bridge construction is a linearly repetitive process which involves the erection of a series of abutments, piers and spans. Such processes provide a great opportunity for performing comprehensive analysis using techniques such as simulation for purposes of productivity improvement (AbouRizk 2010). Examples of past studies that have applied simulation within the bridge construction domain include work done by Ailland et al. (2010), AbouRizk and Dozzi (1993), Huang et al. (1994), Chan and Lu (2005) and Marzouk et al. (2008). In their work, AbouRizk and Dozzi (1993) used CYCLONE to facilitate dispute resolution in bridge jacking operations. Huang et al. (1994) simulated the construction operations of a cable-stayed bridge in Washington by using DISCO. Chan and Lu (2005) used SDESA to simulate field processes for a pre-cast bridge, resulting in optimal solutions to the pre-cast segment inventory problem. Others like Marzouk et al. (2008) utilized STROBOSCOPE to develop a special-purpose simulation model in order to assist in the planning of constructing the bridge decks.

Mobile falsework technology in bridge construction was developed in the 1950s and first adapted in Germany. In contrast with the traditional scaffold construction method to support the entire bridge for concrete casting, the mobile falsework method casts the bridge deck sequentially and thus shortens the total project duration (Pauser 2002). One-time capital investment in the mobile falsework can make up 50$70 \%$ of the total project costs for concrete. Thus, the quantity and the launching strategy of mobile falsework is the primary concern in project planning and execution. Time-cost trade-off analysis by using conventional quantitative methods (such as linear programming) may not be sufficient to factor in all the 
practical constraints. More importantly, critical resources are difficult to identify by applying analytical methods (Melzner et al. 2011). Simulation modeling mimics the real-world construction system based on elaborate computer programming and statistical analysis. The accuracy of simulation results in daily bridge construction operations is determined by the quality of data provided (Ailland et al. 2010). Given valid input data, construction managers can gain insight on construction from the simulation.

In this research study, simulation was employed to compare three alternatives for constructing the pre-stressed concrete bridge using mobile falsework. The alternatives included: (1) the mobile falsework is built from one abutment to the other; (2) the mobile falsework starts from both ends to the middle span; and (3) the mobile scaffold advances from the middle span to both abutments, concurrently. The Umeälv Bridge, a previously constructed bridge which adopted the first alternative as its construction strategy, is presented as a case study. As a result, the activity durations and resource quantities were taken from video and site daily records, which make the simulation model mimic the real construction system and model verification becomes easy. The data of activity durations were fitted based on @ Risk 5.7.1 Industrial for Excel (Palisade Corporation 2012). The fitted distributions are used for input modeling. Model verification is based on tracking the events in a chronological list and evaluating cycle time. Then, the simulation model was validated by comparing site data with results from scenario one. Further, simulation-based analyses were conducted by comparing project time, cycle time (and plotted in stacked chart), utilization rate (busy time/total time) and performing sensitivity analysis (by changing the available resource quantities) for three alternatives. The objective of this paper is to use simulation to examine different bridge falsework construction sequences and their impact on project duration and cost, and to identify critical resources by simulation-based sensitivity analysis. Results from each tested scenario are summarized in the form of charts and tables.

\section{OVERVIEW OF UMEÄLV BRIDGE PROJECT}

The Umeälv Bridge (Figure 1) was designed for carrying railway traffic on the bothnia line in northern Sweden. The bridge was $1937 \mathrm{~m}$ long, $7.5 \mathrm{~m}$ wide and had 38 spans. The deck (superstructure) is a prestressed cast-in-situ concrete structure, while piers, foundations and abutments are all of reinforced castin-situ concrete. The quantity takeoffs for concrete, pre-stressed steel and reinforcing steel were 25000 $\mathrm{m}^{3}, 750$ tons and 3500 tons. The project duration was two and half years. Figure 2 shows the mobile falsework used in this project.

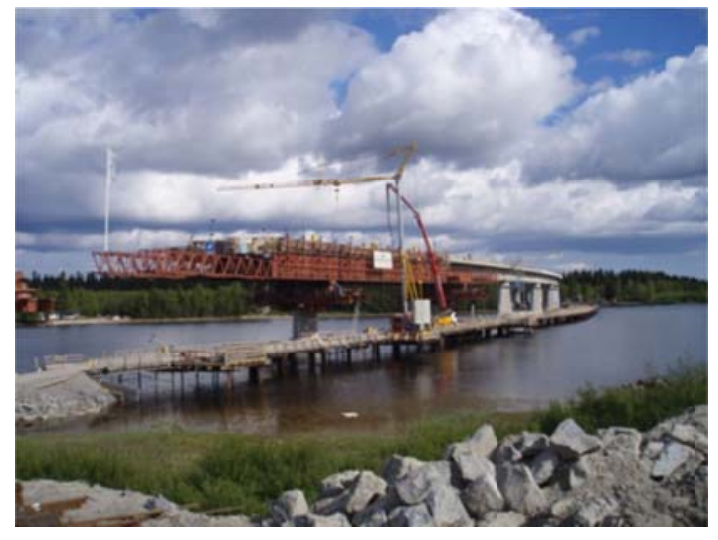

Figure 1: Umeälv Bridge

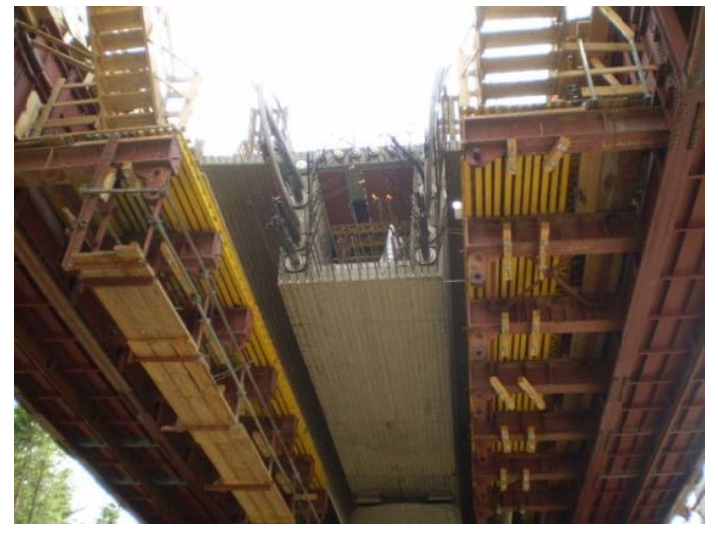

Figure 2: Mobile falsework

\section{CONSTRUCTION SEQUENCE ALTERNATIVES}

In this research, three construction sequences (shown in Figure 3) are studied. In total, 38 spans are planned to be built and the number on the $x$-axis represents the span number. The mobile falsework is advanced from one abutment to the other (Figure 4) as occurred in the actual construction project. The se- 
cond alternative starts the construction simultaneously at abutments, advancing and converging toward the middle span (span 20) (shown in Figure 5). This implies that two sets of mobile falsework are needed. Alternative three shows the construction starts at the middle span, and then advances concurrently to the two abutment ends (Figure 6). The two piers (Piers 19 and 20) are built prior to forming the span (span 19), which sits on the two piers. Two mobile scaffolds are erected, advancing in two opposite directions. Each of the postulated scenarios is simulated in Simphony.Net 4.0 (Mohamed and AbouRizk 2000).

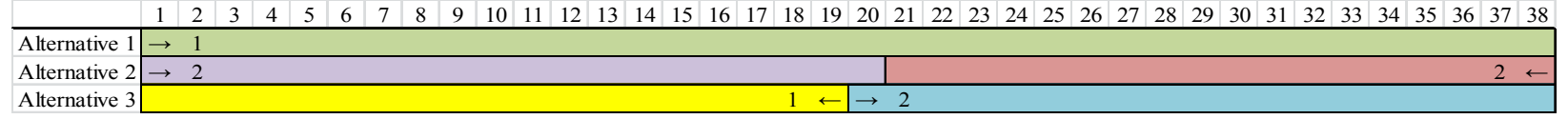

Figure 3: Direction of mobile falsework advancement with respect to the span number

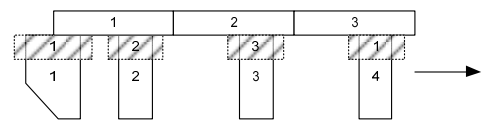

Figure 4: Alternative one

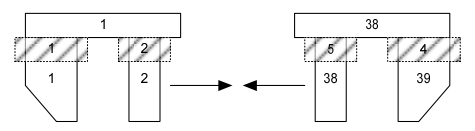

Figure 5: Alternative two

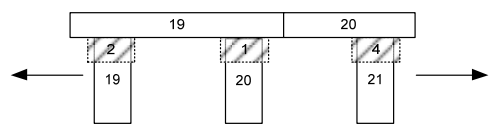

Figure 6: Alternative three

\section{SIMULATION MODELING OF UMEÄLV BRIDGE PROJECT}

\subsection{Abstraction of Specific Bridge Construction Processes}

The Umeälv Bridge is a pre-stressed concrete continuous girder bridge, which consists of abutments, piers and superstructures. Detailed construction processes of abutments, piers and superstructures are represented in the simulation models. Note that the processes for each segment are identical among the three alternatives. Thus, in order to streamline the model and facilitate model reusability, those processes are encapsulated in a "composite" element which is only a "container" housing different elements and has no specific simulation behavior. In addition, the operation processes of installing and advancing mobile falsework are simulated in detail. Despite the fact that each alternative differs in the advancing strategy of mobile falsework, the specific operating processes of mobile falsework remain identical. The following sections describe the construction sequences for abutments, piers, superstructures and mobile falsework.

\subsubsection{Pier}

A pier consists of the pier foundation, shaft and head. It provides main support for the bridge deck and transfers the loads from the spans to the ground. The following construction processes summarize the essential steps to construct one pier: (1) Excavate for pier foundations; (2) Erect reinforcements for pier foundations; (3) Erect formworks for pier foundations; (4) Cast concrete for pier foundations; (5) Cure concrete; (6) Retract formworks on pier foundations; (7) Erect reinforcement for pier shafts; (8) Erect formworks for pier shafts; (9) Cast concrete for pier shafts; (10) Cure concrete; (11) Remove formworks for pier shafts; (12) Erect reinforcements for pier heads; (13) Erect formworks for pier heads; (14) Cast concrete for pier heads; (15) Cure concrete; and (16) Remove formworks for pier heads.

\subsubsection{Abutment}

Abutments are located at the two ends of the bridge, which transfer the loads from the superstructure to the foundation. Similar to pier construction, an abutment is constructed in eleven steps: (1) Excavate for abutment foundation; (2) Erect reinforcements for abutment foundation; (3) Erect formworks for abutment foundations; (4) Cast concrete for abutment foundations; (5) Cure concrete; (6) Retract formworks on abutment foundations; (7) Erect reinforcement for abutment shafts; (8) Erect formworks for abutment shafts; (9) Cast concrete for abutment shafts; (10) Cure concrete; and (11) Remove formworks for abutment shafts. 


\subsubsection{Superstructure}

The functions of a span are basically to support the live and dead loads imposed on the bridge. The dead loads include the drainage pavement, the electrical wire and the railway, while the live loads are mainly associated with the trains. The following seventeen steps take place in series to construct one span: (1) Prepare formworks for girders; (2) Install reinforcements for girder; (3) Install tendons; (4) Close formworks; (5) Cast girders; (6) Cure girders; (7) Strip formworks for girders; (8) Erect formworks for decks; (9) Install reinforcements for deck; (10) Erect formworks for barriers; (11) Cast decks; (12) Cure deck; (13) Stress tendons; (14) Strip formworks for barriers; (15) Strip formworks for decks; (16) Grout tendons and remove formworks; and (17) Move to the next span. It is noteworthy that the last three steps can be conducted concurrently, thereby accelerating the construction.

\subsubsection{Mobile Falsework}

The mobile falsework is known as the most critical driving resource for span construction. It consists of three sets of supporting systems and one working platform. The following six steps are modeled in simulation: (1) The abutments or piers are completed; (2) Assemble supporting systems on piers or abutments with identification number (ID) \#N and \#N+1, respectively; (3) Erect working platform (only when $\mathrm{N}=$ 1); (4) Construct the superstructure with ID \#N and assemble supporting system on the pier with ID \#N+2 in the next span; (5) Launch working platform to construct the superstructure with ID \#N+1; and (6) Disassemble supporting system on pier or abutment with ID \#N.

It should be noted that the supporting system should be installed on the abutments or piers, following the sequence described in each alternative. For instance, in alternative one, the supporting system should be assembled on the piers in the ascending order of pier ID number (following the arrow in Figure 7). However, multiple piers or abutment can be constructed concurrently if sufficient resources are available. Meanwhile, the work content for each abutment or pier is different, and the abutment or pier with larger work content requires longer duration. As a result, there is a possibility of the pier with a larger ID being completed when the pier with a smaller ID is still under construction. For instance, the construction of piers with ID " 5 ", "6" and "7" shown in Figure 7 may be started at the same time, but piers with ID "6" and " 7 " would be finished before the pier " 5 " is completed, as the pier " 5 " has a larger work content. However, piers with ID " 6 " and "7" should not be assembled with supporting systems without the pier with ID " 5 " having been installed, even if they are completed earlier than the pier " 5 ." The reason for this is that the superstructure should only be sequentially constructed from one end to the other due to the structural constraints. Thus, the supporting system should also be installed sequentially.
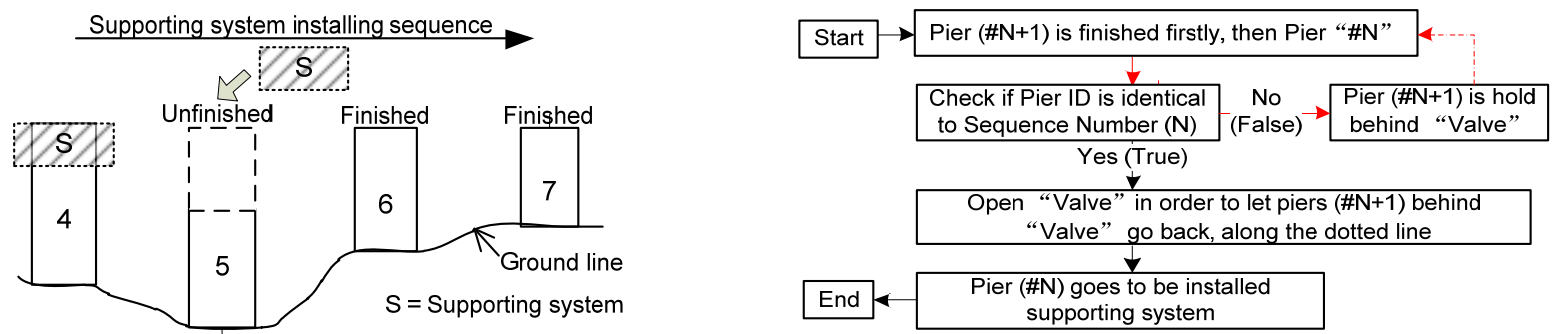

Figure 7: Diagram for installing supporting system Figure 8: Flow chart for installing supporting system

This presents a challenge for simulation modeling: how to control the proceeding sequence of entities which represent piers. To overcome the challenge, a user-written code was embedded within the models to appropriately manipulate the entities. Figure 8 shows the flow chart for controlling the proceeding sequence of entities. In the user-written code, a global variable is defined to keep the sequence number, while another local variable is assigned to entities as an attribute where the identification number is stored. By comparing the two values stored in the variable, the entity could only pass the loop shown as red lines in Figure 8 to be assembled with the supporting system when the identification number is equal 
to the sequence number. Otherwise, the entity which represents a pier with a larger identification number loops back without advancement.

\subsection{Data for Umeälv Bridge}

The actual quantities of the bridge are listed in Table 2 and 3. Table 1 lists the activities' durations and their resource requirements. Also, the priorities in acquiring the resources, which could greatly affect the construction sequence, are defined in Table 1. The data, except distributions of activities' durations, was retrieved directly from video and site daily records, whereas duration distributions were fitted based on each activity duration, using @ Risk 5.7.1 Industrial for Excel. Then, they are used for input data for the simulation.

Table 1: Durations, Resources and Priorities of Activities

\begin{tabular}{|c|c|c|c|c|}
\hline Segment & Activities & Required Resources & Priority & Duration (h) \\
\hline \multirow{8}{*}{$\begin{array}{l}\text { Pier } \\
\text { (Abutment) } \\
\text { foundation }\end{array}$} & Excavate & 1 Excavator & $0(1)$ & $\mathrm{T}(12,20,16)$ \\
\hline & Erect reinforcements & 5 Reinforcement worker & $0(3)$ & $\mathrm{CV}^{*} \mathrm{~W}(2.08,0.017,0) * \mathrm{~T}(0.8,1,0.9)$ \\
\hline & Erect formworks & 1 Formwork for pier & $0(1)$ & $\mathrm{T}(6,10,7.5)$ \\
\hline & & 3 Concrete worker & $0(9)$ & \\
\hline & Cast concrete & 1 Concrete pump & $0(3)$ & $\mathrm{CV}^{*} \mathrm{~W}(2.67,0.019,0.022)$ \\
\hline & & 3 Concrete worker & $1(10)$ & \\
\hline & Cure concrete & & & $\mathrm{T}(8,16,10)$ \\
\hline & Remove formworks & 2 Concrete worker & $2(11)$ & $\mathrm{T}(6,12,8)$ \\
\hline \multirow{7}{*}{$\begin{array}{l}\text { Pier } \\
\text { (Abutment) } \\
\text { shaft }\end{array}$} & Erecting reinforcements & 5 Reinforcement worker & $1(4)$ & $\mathrm{CV}^{*} \mathrm{LN}(0.108,0.070) * \mathrm{~T}(2.8,4.5,3.5)$ \\
\hline & Erect formworks & 1 Formwork for pier & $0(2)$ & $\mathrm{T}(16,24,22)$ \\
\hline & & 3 Concrete worker & $3(12)$ & \\
\hline & Cast concrete & 1 Concrete pump & $1(4)$ & $\mathrm{CV} * \mathrm{~W}(3.669,0.112,0)$ \\
\hline & & 3 Concrete worker & $4(13)$ & \\
\hline & Cure concrete & & & $\mathrm{T}(16,32,24)$ \\
\hline & Remove formworks & 2 Concrete worker & $5(14)$ & $\mathrm{T}(8,16,15)$ \\
\hline \multirow[t]{7}{*}{ Pier head } & Erect reinforcements & 5 Reinforcement worker & 2 & $\mathrm{CV}^{*} \mathrm{~T}(0.0388,0.435,0.23)^{*} \mathrm{~T}(6,9,7)$ \\
\hline & Erect formworks & 1 Formwork for pier & 0 & $\mathrm{~T}(8,20,14)$ \\
\hline & & 3 Concrete worker & 6 & \\
\hline & Cast concrete & 1 Concrete pump & 2 & $\mathrm{CV}^{*} \mathrm{~W}(2.778,0.107,0.0368)$ \\
\hline & & 3 Concrete worker & 7 & \\
\hline & Cure concrete & & & $\mathrm{T}(8,24,20)$ \\
\hline & Remove formworks & 2 Concrete worker & 8 & $\mathrm{~T}(8,16,15)$ \\
\hline \multirow{20}{*}{$\begin{array}{l}\text { Superstruc- } \\
\text { ture }\end{array}$} & Prepare formworks for girders & 2 Concrete worker & 15 & $\mathrm{~T}(1,4,2)$ \\
\hline & Install reinforcements for girders & 6 Reinforcement worker & 15 & $\begin{array}{l}\mathrm{CV} * \mathrm{~W}(2.423,0.049,0.118) \\
{ }^{*} \mathrm{~T}(0.55,0.8,0.7)\end{array}$ \\
\hline & Install tendons & 1 Prestress crew & 15 & $\mathrm{~T}(12,24,18)$ \\
\hline & Close formworks & 4 Concrete worker & 15 & $\mathrm{~T}(2,4,3)$ \\
\hline & Cast girders & 1 Concrete pump & 15 & $\mathrm{CV}^{*}$ Uniform $(0.0404,0.081)$ \\
\hline & & 6 Concrete worker & 15 & \\
\hline & Cure girders & & & $\mathrm{T}(2,4,3)$ \\
\hline & Strip formworks for girders & 2 Concrete worker & 15 & $\mathrm{~T}(1,2,1.5)$ \\
\hline & Erect formworks for decks & $\begin{array}{l}1 \text { Formwork for superstruc- } \\
\text { ture deck }\end{array}$ & 15 & $\mathrm{~T}(1,2,1.5)$ \\
\hline & & 4 Concrete worker & 15 & \\
\hline & Install reinforcements for decks & 5 Reinforcement worker & 15 & $\mathrm{CV}^{*} \mathrm{~W}(3.966,0.0386,0.133) *$ \\
\hline & & & & $\mathrm{T}(0.55,0.8,0.7)$ \\
\hline & Erect formworks for barriers & 2 Concert worker & 15 & $\mathrm{~T}(2,6,4)$ \\
\hline & Caste decks & 1 Concert pump & 15 & $\mathrm{CV}^{*} \mathrm{~W}(3.567,0.027, .033)$ \\
\hline & & 6 Concrete worker & 15 & \\
\hline & Cure decks & & & $\mathrm{T}(4,6,5)$ \\
\hline & Stress tendons & 1 Prestress crew & 15 & $\mathrm{~T}(2,3,2.5)$ \\
\hline & Strip formworks for barriers & 2 Concrete worker & 15 & $\mathrm{~T}(1,2,1.5)$ \\
\hline & Strip formworks for decks & 4 Concrete worker & 15 & $\mathrm{~T}(6,8,7)$ \\
\hline & Groote tendons & 1 Prestress crew & 15 & $\mathrm{~T}(4,6,5)$ \\
\hline \multirow{7}{*}{$\begin{array}{l}\text { Mobile } \\
\text { falswwork }\end{array}$} & Install supporter on Piers & 1 Launching crew & 0 & $\mathrm{~T}(14,20,16)$ \\
\hline & & 1 Supporters & 0 & \\
\hline & Install supporter on Abutments & 1 Launching crew & 2 & $\mathrm{~T}(14,20,16)$ \\
\hline & & 1 Supporters & 0 & \\
\hline & Removing supporter & 1 Launching crew & 5 & $\mathrm{~T}(15,24,16)$ \\
\hline & Install working platform & 1 Launching crew & 7 & $\mathrm{~T}(240,400,320)$ \\
\hline & & 1 Mobile falsework & 0 & \\
\hline
\end{tabular}




\begin{tabular}{|c|c|c|c|c|c|c|c|c|c|c|c|}
\hline & \multicolumn{3}{|c|}{$\begin{array}{l}\text { Launching working platform } \\
\text { disassemble working platform }\end{array}$} & \multicolumn{3}{|c|}{$\begin{array}{l}1 \text { Launching crew } \\
1 \text { Launching crew }\end{array}$} & $\begin{array}{l}10 \\
10\end{array}$ & \multicolumn{2}{|c|}{$\begin{array}{l}\mathrm{T}(6,12,8) \\
\mathrm{T}(160,320,260)\end{array}$} & & \\
\hline \multicolumn{12}{|c|}{$\begin{array}{l}\text { Note: } \mathrm{T}(\mathrm{N} 1, \mathrm{~N} 2, \mathrm{~N} 3) ; \mathrm{T} \text { : Triangular, N1: lower limit, N2: upper limit, and N3: mode value; W(N1, N2,N3); W: Weibull, N1: shape, N2: } \\
\text { scale and N3: location; LN(N1, N2); LN: LogNormal; N1: location ; N2: shape; CV: Concrete Volume }\end{array}$} \\
\hline \# ID & Foundation & Shaft & Head & \# ID & Foundation & Shaft & Head & \# ID & Foundation & Shaft & Head \\
\hline 2 & 112 & 21.4 & 13 & 15 & 434 & 86.5 & 11.5 & 28 & 174 & 57 & 11 \\
\hline 3 & 113 & 27.5 & 12 & 16 & 422.5 & 100 & 11.5 & 29 & 395.5 & 80 & 11.5 \\
\hline 4 & 113 & 29 & 13 & 17 & 455 & 99.5 & 11.5 & 30 & 358.5 & 94 & 12 \\
\hline 5 & 114.5 & 27 & 12.5 & 18 & 364 & 91 & 11.5 & 31 & 410.5 & 90 & 11.5 \\
\hline 6 & 113.5 & 32 & 11.5 & 19 & 107.5 & 49 & 11.5 & 32 & 483 & 100 & 11.5 \\
\hline 7 & 111.5 & 32 & 11.5 & 20 & 293.5 & 119.5 & 11.5 & 33 & 341.5 & 101 & 11.5 \\
\hline 8 & 110 & 46 & 11.5 & 21 & 173 & 48.5 & 11.5 & 34 & 366.5 & 91 & 11.5 \\
\hline 9 & 110 & 46 & 11.5 & 22 & 174 & 47 & 11.5 & 35 & 450 & 90 & 11.5 \\
\hline 10 & 110 & 42 & 11.5 & 23 & 177 & 47 & 11.5 & 36 & 576.5 & 67 & 11.5 \\
\hline 11 & 110 & 42 & 12.5 & 24 & 163 & 47 & 11.5 & 37 & 540.5 & 50 & 11.5 \\
\hline 12 & 113 & 46 & 13.5 & 25 & 172 & 47 & 11.5 & 38 & 155.5 & 42 & 12 \\
\hline 13 & 113.5 & 52.5 & 12 & 26 & 173 & 47.5 & 11.5 & & & & \\
\hline 14 & 212 & 62 & 11.5 & 27 & 174.5 & 46.5 & 11.5 & & & & \\
\hline
\end{tabular}

Table 3: Concrete Volume for Abutments and Superstructures of Umeälv Bridge (Ton)

\begin{tabular}{ccc|ccc}
\hline \multicolumn{3}{c|}{ Abutments } & \multicolumn{3}{c}{ Superstructure } \\
\hline \#ID & Foundation & Shaft & \#ID & Girder & Deck \\
\hline 1 & 76 & 109 & $1 \sim 37$ & 131 & 89 \\
39 & 69 & 156 & 38 & 177 & 134 \\
\hline
\end{tabular}

\subsection{Simulation Model Development}

Simulation models are established in the general purpose template of Simphony, a discrete-event modelling environment. In the general purpose template, each activity in construction is represented by a "Task" element which delays the flow of the entities for the duration of the activity. Another important element is the "Capture" element usually connected at its output point to a "Task" element and having simulation behaviour of occupying or consuming the resource. Entities held by a "Capture" element will not proceed to the "Task" element until they obtain their required resource.

\subsubsection{Alternative One}

The construction sequence is such that work commences at one abutment and advances to the other abutment utilizing one mobile falsework. The construction sequence in alternative one is identical to that implemented in the case study and hence is conducive to model validation. Figure 9 shows us the construction processes of alternative one. The arrows, except the ones between piers or abutments, imply that there is a relationship of 'Finish - to - Start' between two activities, whereas the arrows between piers or abutments only indicate the activities at the tail must start before the ones at the head can commence.

In the simulation model (as shown in Figure 10), the piers, abutments and superstructures are simulated as entities which flow through the model, and construction operations of those segments can be represented by their processes, which are grouped into composites - "Construction of Piers" "Construction of Abutments" and "Construction of Superstructures," respectively. After the entities representing piers or abutments come out from the composites -"Construction of Piers" and "Construction of Abutments," they will be assembled with supporting systems in "Install Abutment Supporting System" and "Install Pier Supporting System," respectively. Then, one abutment and one pier or two piers are batched to trigger their superstructure construction, implying one superstructure entity is released to flow through the composite - "Construction of Superstructures." The interactions among them are simulated by the elements named "Valve" and "Activator." In Simphony, "Valve" element can be used to regulate the flow of entities along the route in a model where it is used by holding them back when in a closed state and letting them flow through when in an open state, and "Activator" element, normally used together with valve elements, is employed to change the state of the valve whenever an entity flows through it. For instance, once the pier with ID " 2 " and the abutment with ID " 1 " are completed and assembled with supporting 
systems, the construction of the 1st superstructure is triggered, using "Activator for superstructure construction" and "Valve for the superstructure" in the model. After finishing the 1st superstructure, the pier with ID " 2 " would be looped back to perform the launching of mobile falsework and the construction of the next superstructure, while the abutment with ID "1" starts the activity of "Removing supporting system" in order to provide the supporting system for the following piers or abutments. The abovementioned operations constitute a loop shown as red lines in Figure 10, and each span of the whole bridge will be constructed in one cycle.

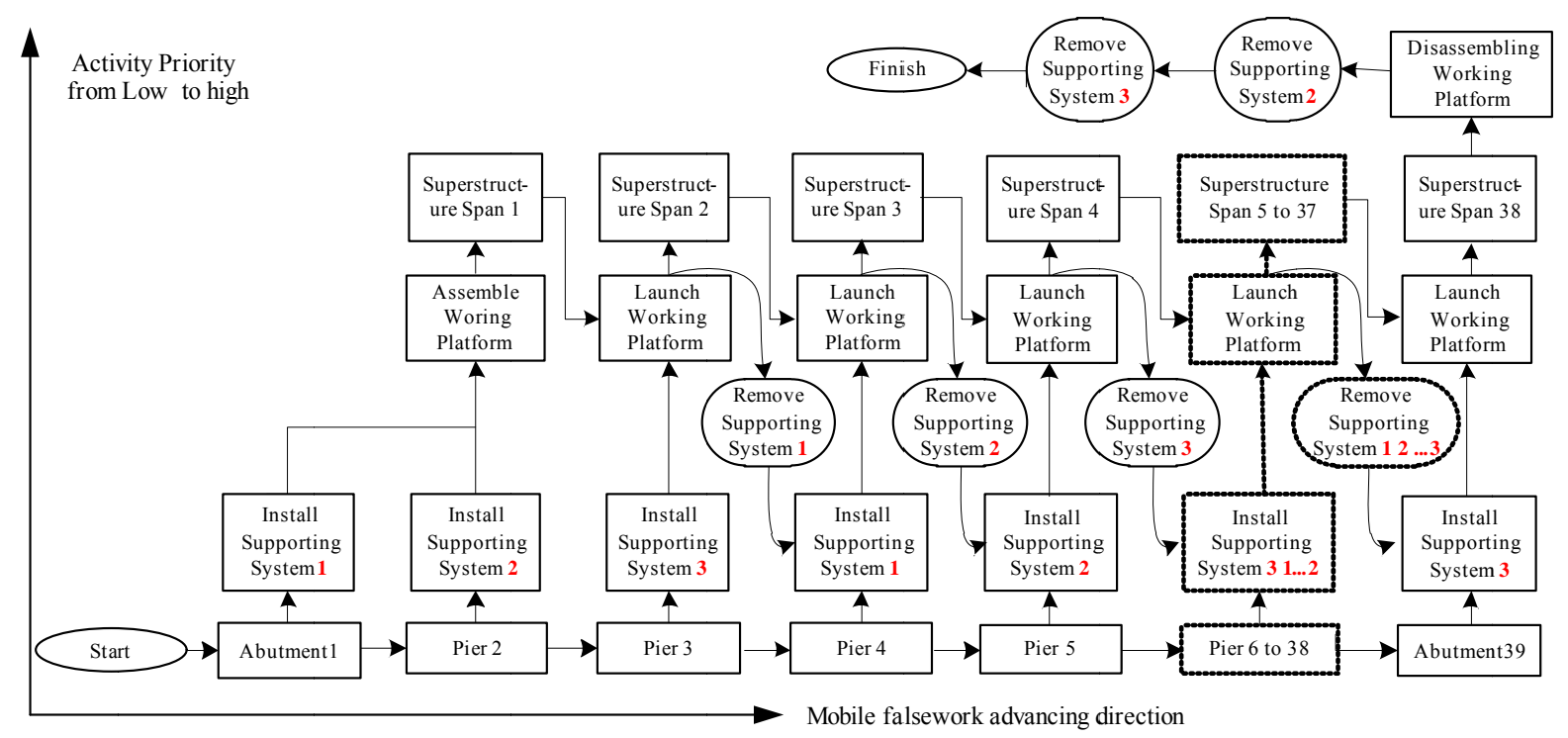

Figure 9: Construction processes for alternative one

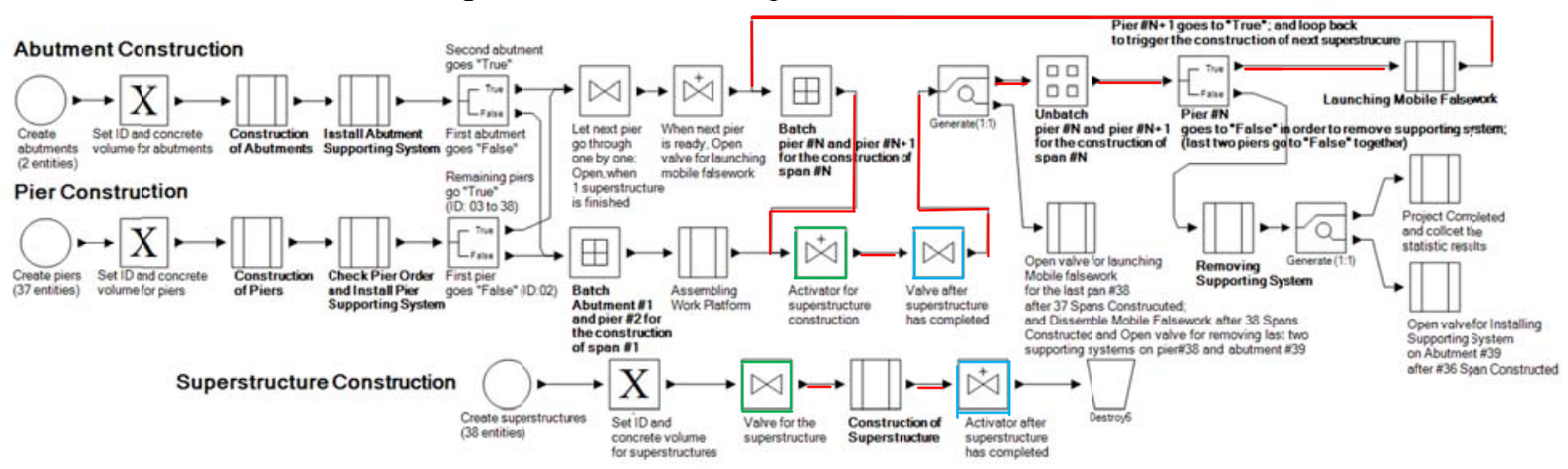

Figure 10: Base model in Simphony for alternative one

\subsubsection{Alternative Two}

The construction workflow is divided into two portions (refer to Figure 3) in alternative two. Each portion is constructed following the same sequences as alternative one. Two separate portions are constructed simultaneously and connected at the 20th span. The construction starts from both abutments converging to the middle span with $100 \mathrm{~m}$ span walking beams (twice the bridge span; on which the working platforms are placed). Towards the end of this construction sequence (at 20th spans), one of the platforms has to be dismantled to give way to the erection of only one platform due to space constraints. Note that the two sets of mobile falsework systems are employed for advancement in this scenario.

\subsubsection{Alternative Three}

The construction sequence in this alternative requires work to start from the middle span and advance in two concurrent directions towards the abutments (refer to Figure 3). Similarly, two mobile falsework sys- 
tems are used; due to space constraints on the site, one set is erected after the other has just advanced to a subsequent span to start the construction work.

\section{RESULTS AND DISCUSSION}

100 simulation runs were conducted for each simulation alternative tested. The simulation models were firstly verified by tracking the chronological list. Then, the cycle times of constructing abutments, piers, and superstructures are analyzed. Further model validation by comparing to site data is discussed (limited to alternative one). Comparisons of the statistical results of resource utilization rates, stacked charts and project duration and cost among the three alternatives are deliberated.

\subsection{Simulation Model Verification and Validation}

To verify the simulation models, the trace functionality provided by Simphony was used to prove that the model replicates the logical construction sequence as intended. Figure 11 shows a screen capture of the trace window from Simphony. User-written code was embedded within the model so that the chronological list of events and the time at which they occurred in alternative one are shown within the trace window. Note "TimeNow" is the logical time measured in hours. The trace was found to follow the expected trend and hence the model can be considered reliable.

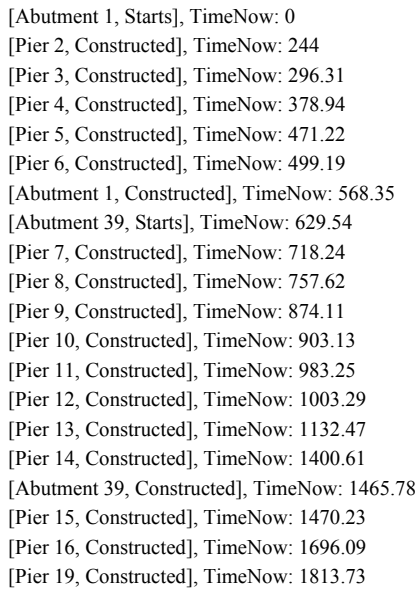

\section{Trace - Alternative 1}

[Pier 17, Constructed], TimeNow: 1883.64
[Pier 18, Constructed], TimeNow: 2037.01
[Pier 22, Constructed], TimeNow: 2104.22
[Pier 21, Constructed], TimeNow: 2194.05
[Pier 20, Constructed], TimeNow: 2328.02
[Pier 23, Constructed], TimeNow: 2351.56
[Pier 24, Constructed], TimeNow: 2438.75
[Pier 25, Constructed], TimeNow: 2450.09
[Pier 26, Constructed], TimeNow: 2583.24
[Pier 27, Constructed], TimeNow: 2653.94
[Launching 2, Starts], TimeNow: 2728.86
[Launching 2, Completed], TimeNow: 2736.09
[Supporting System: 1, Removed], TimeNow: 2736.09
[Pier 28, Constructed], TimeNow: 2768.01
[Pier 29, Constructed], TimeNow: 3049.18
[Pier 30, Constructed], TimeNow: 3166
[Pier 31, Constructed], TimeNow: 3168.25
[Pier 32, Constructed], TimeNow: 3492.2
[Pier 33, Constructed], TimeNow: 3670.87
[Pier 34, Constructed], TimeNow: 3680.37

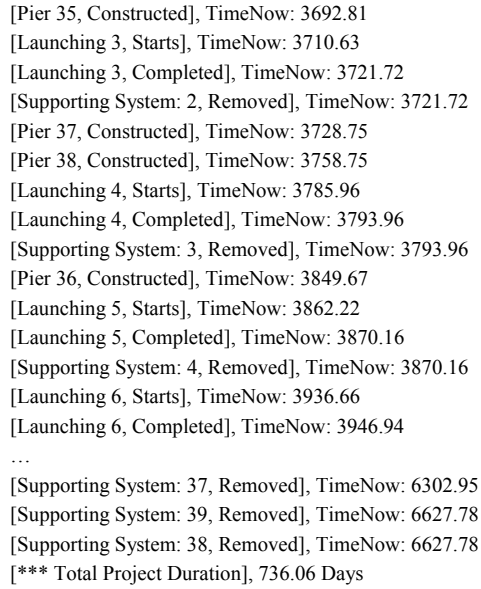

Figure 11: Chronological list

The validation of the simulation model was based on alternative one as the Umeälv Bridge was constructed in the same way. According to Table 4, the mean durations for constructing one abutment and pier were 666.11 and 1324.9 hours, respectively. The long duration of pier construction largely comprises of idling time as piers, competing for limited resources with spans such as the concreting crew, cannot gain the resources in the competition. The average cycle time for the superstructure construction is 149.72 hours. The cycle time simulated was found close to actual site records. The mean total project duration (Table 4) is 752.87 days, which also mirrors the project duration ( 2.5 years with holidays). Thus, it can be concluded that the simulation models and the input modeling are reliable and valid.

Table 4: Average Cycle Times of Constructing Physical Components (100 Simulation Run)

\begin{tabular}{ccccc}
\hline Alternative & Abutment (Hours) & Pier (Hours) & Superstructure (Hours) & Mean Total Duration (Days) \\
\hline 1 & 666.11 & 1324.90 & 149.72 & 752.87 \\
2 & 658.78 & 1440.96 & 204.04 & 637.81 \\
3 & 701.31 & 1347.33 & 161.29 & 645.51 \\
\hline
\end{tabular}




\subsection{Analysis of Simulation Results}

After model verification and validation, two other alternatives were simulated and the simulation results are summarized in Tables 4, 5 and 6. The following subsections discuss these results and their implications in more detail. 


\subsubsection{Stacked Charts}

The stacked charts show that the cycle time for pier foundation construction increases as the project advances. The reason lies in the fact that the lowest priority is given to the pier foundation construction, thus increasing the idle time. The durations of subsequent pier foundation construction increase accordingly. The cycle time of pier shaft and head construction fluctuates slightly since each pier has different quantities of work, but their trend remains the same in three postulated scenarios. The durations for all span construction remain at the same level except the first span. The first span has extremely high cycle time. The reason is that its required resources, in specified quantities, are not available to advance its construction, even if higher priorities are given to the activities in constructing superstructures (refer to Table 1). For example, the cycle time of first span construction (span 19) in alternative three is much longer as the first span construction competes for the resources with the pier construction. The chronological list indicates that most of the piers are completed when the first span is installed. The rest of the spans, in two segments, are constructed smoothly with shorter cycle times.

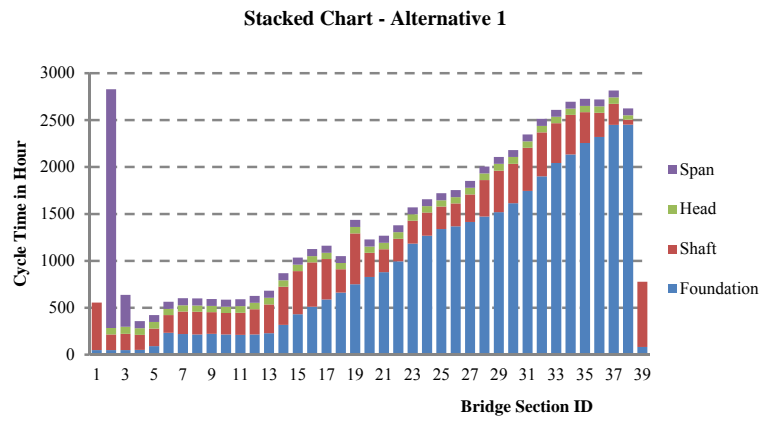

Figure 12: Stacked chart for alternative one

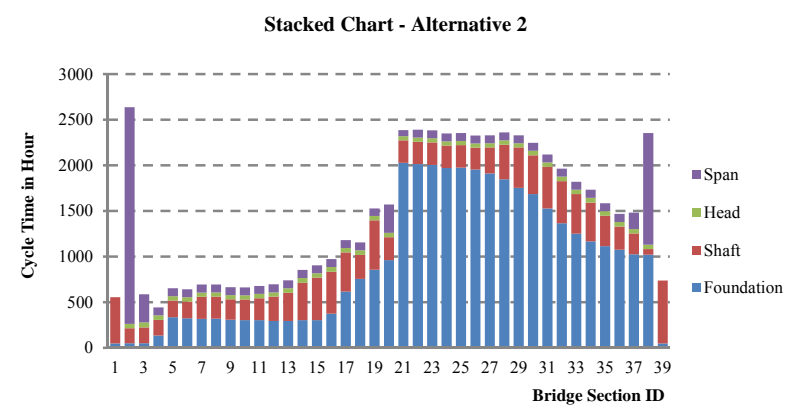

Figure 13: Stacked chart for alternative two

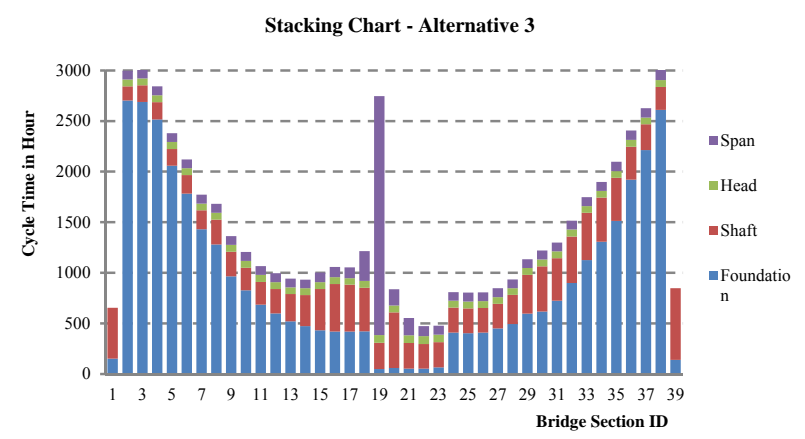

Figure 14: Stacked chart for alternative three

\subsubsection{Utilization Rate and Sensitivity Analysis}

Table 5 summarizes the utilization of each resource (busy time/total time). Generally, the utilization for resources (except for the mobile falsework, including one working platform and three pier supporting systems) in alternatives two and three is higher than in alternative one. This is realistic as the resources are shared between two separate, concurring work flows. The reduction in the rate of utilization of mobile falsework is due largely to doubling its quantities. Another interesting observation is that the utilizations of reinforcement workers and mobile falsework are relatively high, implying that they are critical resources and have less idle time. Extra care should have been taken to decide the availability limits of these critical resources. Sensitivity analysis was also done by adjusting the quantities of reinforcement workers for three alternatives in regard to the project time (Table 6).

One important observation is that the larger the number of reinforcement workers, the shorter the project duration in all three alternatives. The duration could shorten by about 100 days by adding 5 reinforcement workers, and shorten by 190 days by providing a total of 25 workers. This "time crash" effect 
stabilizes beyond 35 reinforcement workers. The above demonstrates the value and insight gained from conducting sensitivity analysis with the aid of simulation.

Table 5: Resource Utilization Results from the Simulation (Random Seed: 5)

\begin{tabular}{lccc}
\hline Resource & Alternative 1 & Alternative 2 & Alternative 3 \\
\hline Formwork for Superstructure & 0.2057 & 0.2675 & 0.2684 \\
Formwork for Pier Head & 0.084 & 0.1056 & 0.102 \\
Formwork for Shaft & 0.1125 & 0.1388 & 0.1327 \\
Formwork for Foundation & 0.0776 & 0.0958 & 0.0918 \\
Concrete Pump & 0.173 & 0.1981 & 0.1977 \\
Concrete Worker & 0.1389 & 0.1686 & 0.1624 \\
Excavator & 0.0904 & 0.113 & 0.1081 \\
Reinforcement Worker & $\mathbf{0 . 5 8 1 6}$ & $\mathbf{0 . 6 7 0 6}$ & $\mathbf{0 . 6 9 9 4}$ \\
Pre-stress Crew & 0.1413 & 0.1725 & 0.1705 \\
Launching Crew & 0.2417 & 0.2985 & 0.2873 \\
Working Platform & $\mathbf{0 . 9 1 1 1}$ & $\mathbf{0 . 7 3 8 6}$ & $\mathbf{0 . 6 4 6 4}$ \\
Supporting System (Segment 1) & $\mathbf{0 . 9 2 4 6}$ & $\mathbf{0 . 8 5 8 5}$ & 0.7983 \\
Supporting System (Segment 2) & - & 0.6636 & $\mathbf{0 . 8 5 9 6}$ \\
\hline
\end{tabular}

Table 6: Sensitivity Analysis for Reinforcement Workers

\begin{tabular}{|c|c|c|c|c|c|c|c|c|c|c|c|c|c|}
\hline \multirow{2}{*}{ Reinforcement Worker } & \multicolumn{13}{|c|}{ Quantities/Project duration (Day) } \\
\hline & 15 & 20 & 25 & 30 & 35 & 40 & 45 & 50 & 55 & 60 & 65 & 70 & 75 \\
\hline Alternative 1 & 753 & 634 & 568 & 519 & 484 & 461 & 446 & 433 & 421 & 414 & 409 & 410 & 407 \\
\hline Alternative 2 & 638 & 521 & 454 & 409 & 375 & 352 & 338 & 326 & 320 & 318 & 316 & 318 & 319 \\
\hline Alternative 3 & 646 & 520 & 454 & 410 & 384 & 369 & 356 & 364 & 339 & 336 & 336 & 337 & 338 \\
\hline
\end{tabular}

\subsubsection{Comparison of Project Duration}

Table 4 tabulates the total project durations with respect to all alternatives. The total project duration reduces significantly from 753 days to 638 days (alternative two, reducing by $15.3 \%$ ), and to 646 days (alternative three, reducing by $14.3 \%$ ). It is observed that the duration would be not half of the original duration if the bridge were constructed in two simultaneous workflows. Despite doubling the quantities of mobile falsework, driving resources such as the pre-stressing crew, the launching crew and reinforcement workers would be shared between two separated workflows. Meanwhile, this also results in prolonging the average durations for piers and superstructures in alternative two and three (as shown in Table 4). The quantities of shared resources remain the same in all alternatives, and the shared resources would work around the clock in two portions of construction workflow, which increases their own utilization rate, but some activities could still be delayed as the shared resources are occupied by other activities. Another interesting observation is that the average cycle time of abutments in alternative two is shortest, followed by the ones in alternative one and two sequentially. The reason is that, in alternative two, two abutments are constructed concurrently at the beginning of the project while only one abutment in alternative one could be constructed, with no abutment in alternative three being built at the start of the project. It means constructing abutments after piers will increase the average cycle time for abutments. This is realistic as the idle time in pier or abutment foundation construction increases as the project advances (refer to Figure 12 to 14$)$.

\subsubsection{Comparison of Project Cost}

In the simulation models, the material cost is embedded and simulated by multiplying quantities of materials and unit cost of materials. The materials, including concrete, reinforcement and tendon are taken into consideration in this research. In addition, the quantity of each material was obtained from the construction site, and the inflation of unit costs was also simulated in the model, by a normal distribution as a fluctuation factor. The material cost results are tabulated in Table 7. According to Table 7, material costs in all three alternatives generally remain the same as identical quantities of materials are used in all scenarios, and the differences only indicate the fluctuation of materials' unit cost during construction, which, on the other hand, corroborate that simulation models are reliable. 
Labor cost is estimated by multiplying the project duration and associated hourly unit costs. In light of the cost record on the construction site, the hourly unit cost for all the labors in the project is around $\$ 1665$. As for the equipment cost, it is mainly dependent on the cost of mobile falsework. Table 7 lists the approximate equipment cost based on the site record and quantities of mobile falseworks deployed in each alternative. The total direct cost shown in the last column of Table 7 is the sum of labour cost, equipment cost and material cost. The estimation shows that the direct cost for alternative one decreases by around $18 \%$, compared with the costs of alternative two and three. However, the time-dependent overhead cost for alternative one would be much higher due to the longer project duration.

Table 7: Simulation Results of Cost Estimation for Three Alternatives

\begin{tabular}{cccccc}
\hline Alternative & Duration (hours) & Labor Cost & $\begin{array}{c}\text { Equipment Cost } \\
\text { (Including mobile falsework cost) }\end{array}$ & Material Cost & Total direct Cost \\
\hline 1 & 6780.02 & $\$ 11,288,738.63$ & $\$ 6,000,000.00$ & $\$ 8,313,354.06$ & $\$ 25,602,092.69$ \\
2 & 5883.60 & $\$ 9,796,197.16$ & $\$ 12,000,000.00$ & $\$ 8,311,789.39$ & $\$ 30,107,986.55$ \\
3 & 6042.03 & $\$ 10,059,974.62$ & $\$ 12,000,000.00$ & $\$ 8,319,652.77$ & $\$ 30,379,627.39$ \\
\hline
\end{tabular}

\section{CONCLUSION}

Simphony was successfully applied to simulate the Umeälv Bridge construction project and evaluate mobile falsework advancing methods. Simulation models developed were verified and validated. Verification was achieved by tracing a list of simulated events and observing relevant statistics such as cycle time. The models were proven to be valid by comparing their results to data from the site. Although, in this project, alternative one had been selected, the manager made this decision based only on his experience, without simulation decision support. While the simulation results indicate that the construction starting from the two ends to the middle or from the middle to the two abutments could reduce around $15 \%$ of the total project duration and increase around $18 \%$ of the total direct cost, and constructing the bridge from the middle to both ends or from the two ends to the middle makes little difference. Another interesting finding is reinforcement workers and mobile falsework are identified as critical resources. The increase of reinforcement workers could significantly reduce the project completion time. In addition, it is obvious that although alternative one has longer project duration, causing a much higher overhead cost, the direct (including mobile falsework) cost for it would be considerably lower than alternatives two or three. Each alternative possesses its pros and cons. This research study demonstrates the feasibility of applying Simphony to bridge construction, and concludes that construction managers could make decision with confidence relying on simulation rather than experience in construction planning.

\section{REFERENCES}

AbouRizk, S. 2010. "Role of Simulation in Construction Engineering and Management." J. Constr. Eng. Manage., 136(10): 1140-1153

AbouRizk, S., and Dozzi, S. 1993. "Applications of computer simulation in resolving construction disputes.” J. Constr. Eng. Manage., 119(2): 355-373

Ailland, K., Bargstädt, H. and Hollermann, S. 2010. "Construction process simulation in bridge building based on significant day-to-day data." Proceedings of 2010 Winter Simulation Conference, Balti more, Maryland, USA., 3250-3261

Chan, W. H. and Lu, M. 2005. "Logistics and operations simulation in precast viaduct construction: case study." Proceedings of the 2005 ASCE International Conference on Computing in Civil Engineering, Cancun, Paper No. 131

Huang, R., Grigoriadis, A. M. and Halpin, D. W. 1994. "Simulation of cable-stayed bridges using Disco." Proceedings of 1994 Winter Simulation Conference, San Diego, CA, USA., 1130-1136

Marzouk, M., Said, H. and EI-Said, M 2008. "Special-Purpose Simulation Model for Balanced Cantilever Bridges"., J. Bridge Eng. 13(2): 122-131

Melzner, Jürgen, Hollermann, Sebastian \& Bargstädt, Hans-Joachim. 2011. "Detailed Input data Source for Construction Process Simulation: Approach to connect different data source for discrete-event 
Liu, Siu, Hollermann, Ekyalimpa, Lu, AbouRizk, and Bargstädt

simulation." SIMUL 2011 The Third International Conference on Advances in System Simulation, $140-143$

Mohamed, Y., and AbouRizk, S. 2000. "Simphony: an integrated environment for construction simulation." Proceedings of the 2000 Winter Simulation Conference, Orlando, FL, USA, 2: 1907-1914

Palisade Corporation. 2012. “@Risk Industrial 5.7.1”USA.

Pauser, Alfred. 2002. "Massivbrücken ganzheitlich betrachtet: Geschichte - Konstruktion - Herstellung Gestaltung." Düsseldorf: Verlag Bau und Technik

\section{AUTHOR BIOGRAPHIES}

HE-XU LIU is a Ph.D. student at the Hole School of Construction Engineering in the Department of Civil and Environmental Engineering at the University of Alberta. His research is bridge construction simulation and building information modeling (BIM) of dynamic temporary facilities in construction. His email address ishexu@ualberta.ca.

MING-FUNG FRANCIS SIU is currently a Ph.D. student at the Hole School of Construction Engineering in the Department of Civil and Environmental Engineering at University of Alberta. He was honored on the Dean's honor list upon graduation in 2009, and was certified as Project Management Professional (PMP)® in 2010. His research interests are in the integration of applied photogrammetry, augmented reality and project scheduling simulation modeling to advance knowledge and practice of industrial construction/maintenance project planning and control. His email is siumingfungfrancis@gmail.com.

SEBASTIAN HOLLERMANN is a civil engineer in the Department of Building Operations and Building Processes, Bauhaus-University Weimar. He is completing his dissertation on the chair of construction engineering and management at the Bauhaus-University in Weimar. Before moving to academia, he accumulated several years of construction site management experience for bridges at Bilfinger Berger Ingenieurbau GmbH, Scandinavian Branch, Göteborg, Sweden. His research interests are in construction process simulation of concrete bridge superstructure building based on significant day-to-day data including costs. His email address is sebastian.hollermann@uni-weimar.de.

RONALD EKYALIMPA is a Ph.D. student at the Hole School of Construction Engineering in the Department of Civil and Environmental Engineering at the University of Alberta. His research focus is in the area of construction simulation. His email address is rekyalimpa@ualberta.ca.

MING LU is an Associate Professor in the Department of Civil \& Environmental Engineering at the University of Alberta. He has been committed to achieving excellence in research and teaching in areas of construction engineering and project management. His research interests are construction surveying and automation, operations simulation and scheduling in construction. His email address is mlu6@ualberta.ca.

SIMAAN ABOURIZK holds an NSERC Senior Industrial Research Chair in Construction Engineering and Management at the Department of Civil and Environmental Engineering, University of Alberta, where he is a Professor in the Hole School of Construction Engineering. He received the ASCE Peurifoy Construction Research Award in 2008. His email address is abourizk@ualberta.ca.

HANS-JOACHIM BARGSTAEDT is a Professor for Construction Engineering and Management at the Bauhaus-University Weimar. His research fields are construction processes, construction management, simulation in construction, and construction in the built environment and lifecycle considerations. His email is hans-joachim.bargstaedt@uni-weimar.de. 